\title{
Description of two new species of Cossidae (Lepidoptera) from China
}

\author{
Povilas Ivinskis ${ }^{1, \dagger}$, Jolanta Rimsaite ${ }^{1, \neq}$, Aidas Saldaitis ${ }^{1, \S}$, Roman Yakovlev ${ }^{2,1}$ \\ I Nature Research Centre, Akademijos str. 2, LT-08412 Vilnius-21, Lithuania 2 Altai State University, \\ South-Siberian botanical garden, Lenina 61, Barnaul, 656049, Russia \\ † urn:lsid:zoobank.org:author:03895A6C-9E57-4B74-9D00-5C9D023920D5 \\ † urn:lsid:zoobank.org:author:9754C97B-5324-42CE-96F5-64E91E13C7E7 \\ § urn:lsid:zoobank.org:author:1C168900-4B0F-4999-895D-FAB0B16B14C1 \\ | urn:lsid:zoobank.org:author:3331547B-6B8F-48DE-B6B4-1619D2416228
}

Corresponding author: Povilas Ivinskis (ivinskis@ekoi.lt)

Academic editor: Carlos Peña | Received 13 December 2011 | Accepted 17 April 2012 | Published 8 May 2012

urn:lsid:zoobank.org:pub:ADD89AF0-654F-4877-85EC-FB6BF78C345F

Citation: Ivinskis P, Rimsaite J, Saldaitis A, Yakovlev R (2012) Description of two new species of Cossidae (Lepidoptera) from China. ZooKeys 192: 35-49. doi: 10.3897/zookeys.192.2611

\begin{abstract}
Two new Cossidae species from China's Zhejiang and Sichuan provinces are described. The new species Phragmataecia monika sp. n. and Patoptoformis rimsaite sp. n. superficially resemble related congeners but can be distinguished by differences in wing pattern, genitalia and distribution. Checklists of the genera Phragmataecia and Patoptoformis are presented.
\end{abstract}

\section{Keywords}

Cossidae, Phragmataecia, Patoptoformis, new species, China

\section{Introduction}

During a study of the Cossidae collection at the Zoologische Staatssammlung der Bayerischen Staaten (Munich, Germany)/Museum of Thomas Witt (Munich, Germany) the authors found two unknown specimens from China belonging to the genera Phragmataecia and Patoptoformis. After examining their morphology relative to related species the authors are describing the new species herein.

Copyright Povilas Ivinskis et al. This is an open access article distributed under the terms of the Creative Commons Attribution License 3.0 (CC-BY), which permits unrestricted use, distribution, and reproduction in any medium, provided the original author and source are credited. 


\section{Materials and methods}

The material was collected in 2010, during May and July, using artificial light. Taxonomic nomenclature and checklists used in this study were compiled pursuant to consulting expert taxonomists and relevant literature (Schoorl 1990, Yakovlev 2011).

Abbreviations of depositories:

ZSSM/MWM collection of Zoologische Staatssammlung der Bayerischen Staaten (Munich, Germany)/Museum of Thomas Witt (Munich, Germany).

\section{Systematic accounts}

\section{Genus Phragmataecia Newman, 1850}

http://species-id.net/wiki/Phragmataecia

Phragmataecia Newman, 1850, Zoologist 8: 2931

Type species. Noctua arundinis Hübner, [1808]

Members of this genus are generally medium sized with very long abdomens, especially in females, and long bipectinate antennae. In males the length of pecten abruptly shortens to the distal part of tip, while in females pecten length is short to the tip of antenna as near invisible papilla. Coloration is white to black with unexpressed wing patterns except small black dots between the vein of the forewing in females.

Male genitalia. Uncus base short and wide, tip acute; tegumen medium size; gnathos reduced; valvae lancete-shaped with even edges, gradually narrowing to rounded tip; juxta wide with two lateral outgrowth patches; saccus elongated, semioval form; aedeagus long, weakly hooked and slightly longer than valva; vesica without cornutus, with pale indistinct opening.

Female genitalia. Long oviductus; papillae anales elongated, ellipse form; apophyses posteriores about 1.5 times longer than apophysis anterioris; ostium opening immersed, cup-like; postvaginal plate indistinct; ductus thin, long; bursa sack rounded, small without signum and with insignificant bulla on lateral side.

Distribution. 39 species distributed in Old world excluding Papuan and Australian ranges.

\section{Phragmataecia monika Yakovlev \& Saldaitis, sp. n.} urn:lsid:zoobank.org:act:A8A6C34C-3A71-43D5-8F96-754BCA5B921A http://species-id.net/wiki/Phragmataecia_monika Figs $1-4$

Holotype. male (Fig. 1), China, Qin Liang Feng m.800 Zhejiang prov. [province] 2930.V.2010 A. Floriani (slide No.JB1620), (deposited in ZSSM/MWM). 

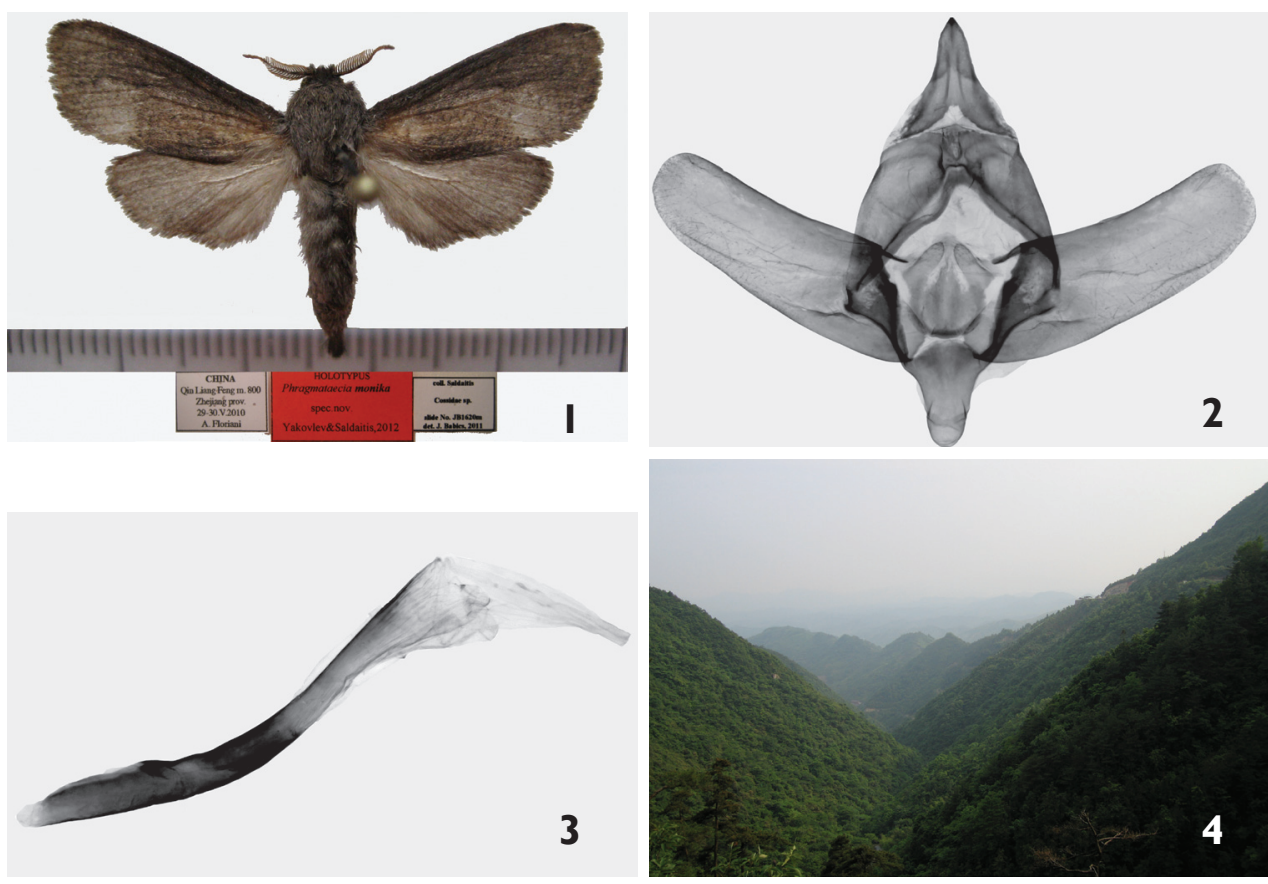

Figures I-4. Phragmataecia monika Saldaitis \& Yakovlev sp. n. I Ph. monika, male, holotype, China, Zhejiang prov. $2 \mathrm{Ph}$. monika, holotype, male genitalia capsule prep. Nr. UFO $13 \mathrm{Ph}$. monika, holotype, male genitalia aedeagus prep. Nr. UFO 14 Type locality of $P h$. monika, China, Zhejiang prov.

Diagnosis. Externally the new species is most similar to sibling species Phragmataecia cinnamomea Wileman, 1911, Phragmataecia hummeli Bryk, 1942 and to Phragmataecia fusca Wileman, 1911. Ph. cinnamomea differs by having a yellow-brown body and wings, veins covered with dark brown scales in the postmedian forewing and dark brown dots in the terminal area (Fig. 5) and male genitalia valvae which widen to the apical part (Fig. 6). Ph. hummeli has a grey-brown body and unicolor wing pattern with forewings lighter brown and hindwings grey brown (Fig. 7). Its male genitalia differ by the pointed shape of the valvae, the rounded and very wide saccus and straight aedeagus (Fig. 8). Ph. fusca has a dark yellow-brown body (Fig. 9), forewings dark brown in postmedian part, and reddish-brown hindwings. Its male genitalia valvae are rounded at the apical part (Fig. 10).

Description. Male (Fig. 1): Forewing length of holotype $14 \mathrm{~mm}$, wingspan 31 $\mathrm{mm}$. Antennae one-third the length of forewing; last third strongly bipectinate with very short triangular pecten. Ground color of forewings blackish brown; median part of wing from base to inner edge yellow brown extending to $j$-shaped wing edge; cilia yellow mixed with brown scales; hindwing unicolor yellow, cilia greyish brown; dorsal forewing dark brown, anal edge grey; dorsal hindwing dark brown, costal area black brown. Head, thorax blackish brown. 

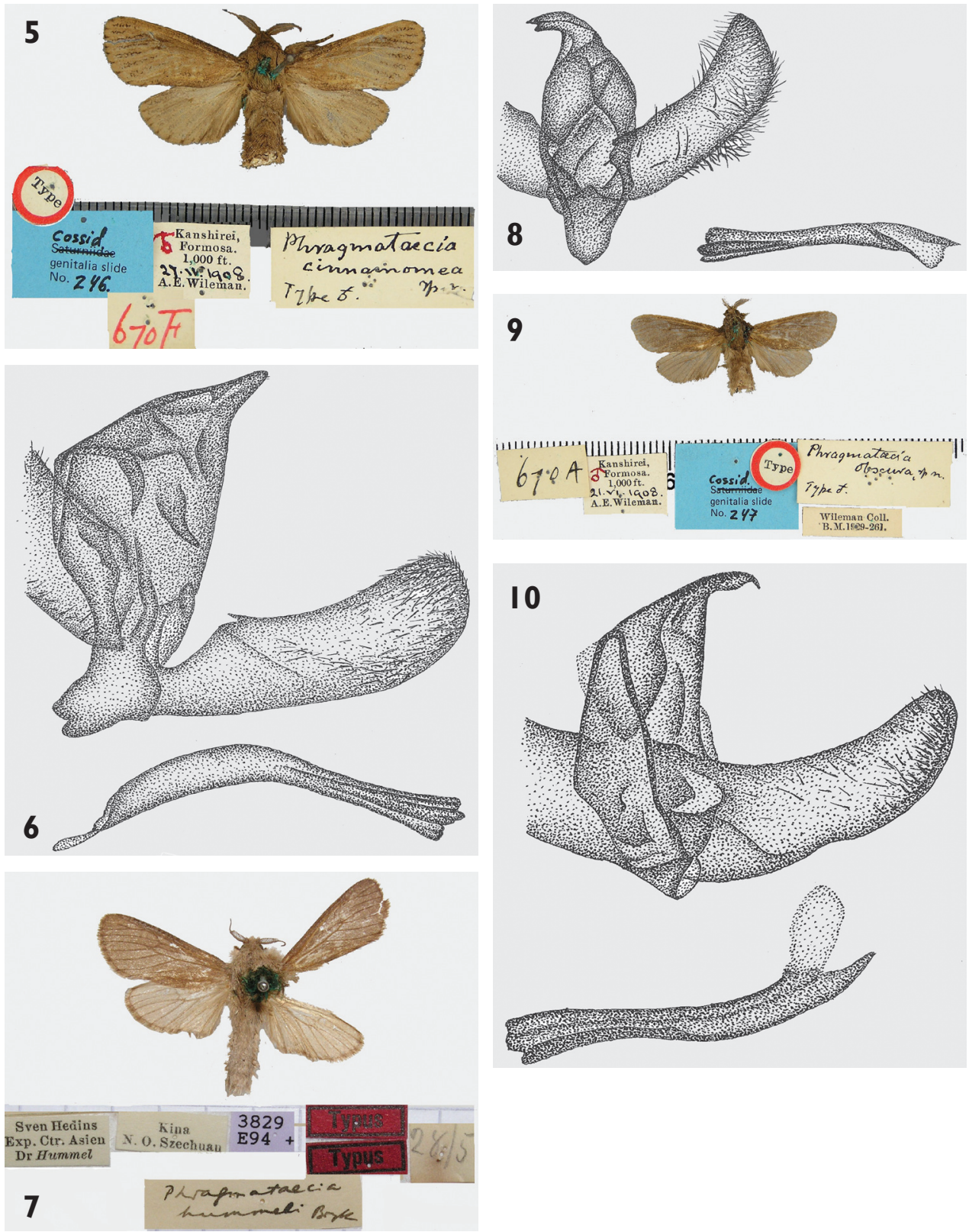

Figures 5-10. Phragmataecia spp., adults and genitalia. 5 Ph. cinnamomea Wileman, adult, holotypus. 6 Ph. cinnamomea Wileman, holotypus, male genitalia 7 Ph. hummeli Bryk, adult, holotypus 8 Ph. hummeli Bryk, holotypus, male genitalia 9 Ph. fusca Wileman (= Phragmataecia obscura Wileman, 1911 adult 10 Ph. fusca male genitalia. 
Male genitalia (Figs 2, 3): Uncus wide, strong narrowing to acute tip; valvae almost the same width as length, flat tips with long blunt outgrowths at base; tegumen wide in medial part with plunging wide neckline; saccus long, narrow, rounded; juxta wide with a pair of lateral processes; aedeagus longer than valva, thin, curved and at the tip twice wider than base.

Female genitalia. Unknown.

Bionomics and distribution. Known only from the Qin Liang Feng Shan mountains in Zhejiang province of eastern China (Fig. 4), Phragmataecia monika is likely endemic to East China. The single male specimen was attracted to light in late May at an altitude of $800 \mathrm{~m}$ in mountainous virgin mixed forest habitat dominated by various broad-leaved trees such as oak Quercus dentata, Quercus glauca, poplar Populus cathayana, P. simonii, elm Ulmus parvifolia, rhododendron Rhododendron brachycarpum, Rh. dauricum, and bamboo Phyllostachys spp., Borinda spp., Fargesia spp. Suspected host plants are Phragmites spp.

Etymology. The new species is named after Monika Rimsaite, daughter of the second author.

Key to species Phragmataecia related to $P h$. monika based on external characters

$1 \quad$ Forewings dark colored ............................................................. 2

Forewings light colored.................................................................. 3

2 Forewings blackish brown..................Ph. monika sp. n., China: Zhejiang

- $\quad$ Forewings dark brown ................................. Ph. fusca Wileman, Taiwan

3 Forewings light brown ..................................Ph. hummeli Bryk, China

- $\quad$ Forewings yellow brown with dark brown scales group and dots in terminal part.................................... Ph. cinnamomea Wileman, China, Taiwan

Key to species Phragmataecia related to $P h$. monika based on male genitalia

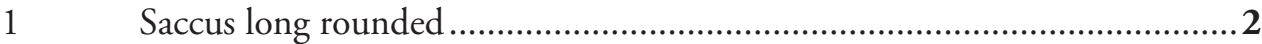

- Saccus short or slightly bilobed ................................................... 3

2 Valva almost the same width as length .... Ph. monika sp. n., China: Zhejiang

- Valva in the apical part pointed ....................... Ph. hummeli Bryk, China

3 Valva rounded, wider in the apical part.

Ph. cinnamomea Wileman, China, Taiwan

- Valva in the apical part slightly narrowed, rounded

Ph. fusca Wileman, Taiwan 
Genus Patoptoformis Yakovlev, 2006

http://species-id.net/wiki/Patoptoformis

Patoptoformis Yakovlev, 2006, Tinea, 19 (3): 203.

Type species. Patoptoformis hanuman Yakovlev, 2006.

Small dark colored moths with dark hair densely covering the body. Antennae bipectinate. Forewing with a scarcely seen streaky pattern; hindwing dark without pattern; fringe evenly dark on both wings. Sexual dimorphism weakly expressed but female somewhat larger than male with wider wings and non-pectinate antennae.

Male genitalia. Uncus long, narrowly triangular with pointed apex; gnathos arms long and densely covered with spinules; valva with costal crest, blunt apex and scarcely noticeable transition between sclerotized and membranous parts, sclerotization gradually weakening towards apex; arms of transtilla small, pointed; juxta small; saccus very poorly expressed; aedeagus short, vesica opening occupies a dorso-apical position and comprises half of aedeagus length; vesica without cornuti.

Female genitalia. Papillae anales elongated with rounded apices; apophyses posteriores thin, twice as long as anteriores; ostium opening immersed, fissure-like, surrounded by cordate rim; ductus bursae membranous, long and narrow; bursa elongate, gradually inflating to apex; ductus seminalis thin, enters bursa near its junction with ductus bursae.

Distribution. Three species distributed in NE India (Assam), Nepal, SE China (Sichuan).

\section{Patoptoformis rimsaitae Saldaitis \& Yakovlev, sp. n.} urn:lsid:zoobank.org:act:2F9D4618-3ED3-454E-A454-65B85A0D89EB http://species-id.net/wiki/Patoptoformis_rimsaitae

Figs 11-14

Type material. Holotype: male China, Sichuan prov. [province], Env. [environs] Mianning Ling Shan Mts. [mountains], h[high], -3760 m 01-03. 07. 2010, local collector leg. (slide No.JB1620), (deposited in ZSSM/MWM).

Diagnosis. Externally the new species is most similar to sibling species Patoptoformis ganesha (Yakovlev, 2004) and Patoptoformis hanuman Yakovlev, 2006. Unlike the new species, $P$. ganesha has dark forewings generally with a row of narrow transversal bands in medial and submarginal zones and black hindwings with a black fringe (Fig. 15). Male genitalia in P. ganesha differ as its uncus is triangular, broad gnathos is densely set with spinules, valvae are cut near apex, arms of transtilla are hook-like and saccus is rounded (Fig. 16). In P. hanuman the forewings are brown with a faint black streaky pattern with a clear submarginal streak and spot in the distal area and hindwings are dark brown, almost black (Fig. 17, 19). Male genitalia differ in shape of 

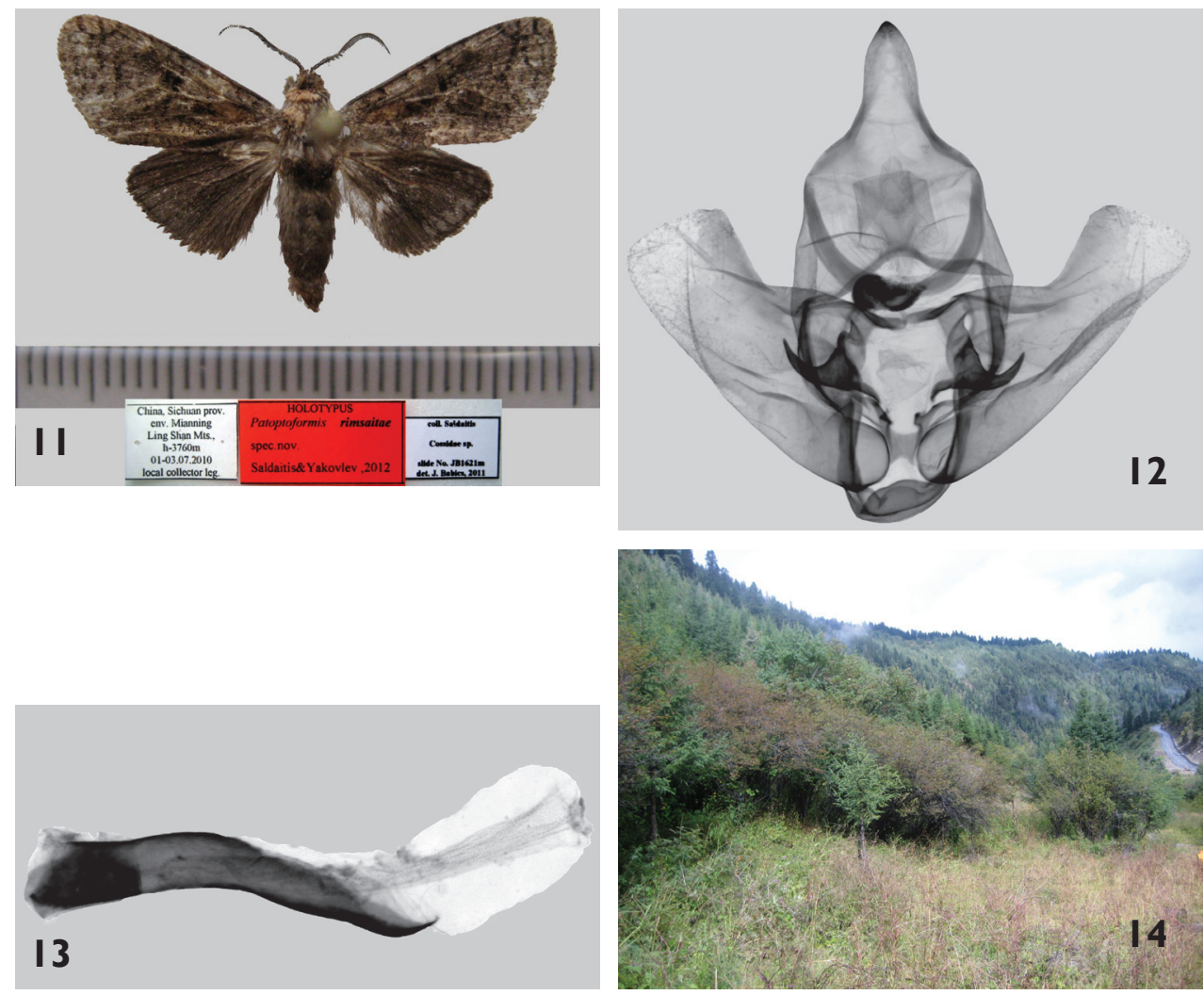

Figures I I-I 4. Patoptoformis rimsaitae Saldaitis \& Yakovlev sp. n. I I P. rimsaitae Saldaitis \& Yakovlev, holotype, Sichuan province $\mathbf{I} 2 P$. rimsaitae, holotype, male genitalia, capsule, prep. Nr. UFO 2 I3 $P$. rimsaitae, holotype, male genitalia, aedeagus, prep. Nr. UFO 2 I4 Type locality $P$. rimsaitae, China, Sichuan.

the valvae which are narrower, the gnathos arms which are thicker and aedeagus which is somewhat curved in the middle (Fig. 18).

Description. Male (Fig. 11): Forewing length of holotype $11 \mathrm{~mm}$; wingspan 24 $\mathrm{mm}$. Antennae almost half as long as forewing, strongly bipectinate and last third with very short triangular pecten; ground color of forewings grey blackish with large yellow patch in middle of basal area, middle part of wing from base to inner edge yellow brown, cilia yellow mixed with brown scales; hindwing unicolor yellow, cilia greyish brown; upper side of forewing dark brown, anal edge grey; upper side of hindwing dark brown, costal area black brown; head, thorax blackish brown.

Male genitalia (Figs 12, 13): Uncus wide with blunt tip; gnathos wide but arms narrow; valvae short, very wide at base narrowing to middle then widening abruptly at tip; arms of transtilla hook-like, thin, acute in tip; saccus wide, rounded; aedeagus almost the same length as valva, weakly curved with sharp curved tip; vesica like equilateral sack with opening size more than half of aedeagus length. 


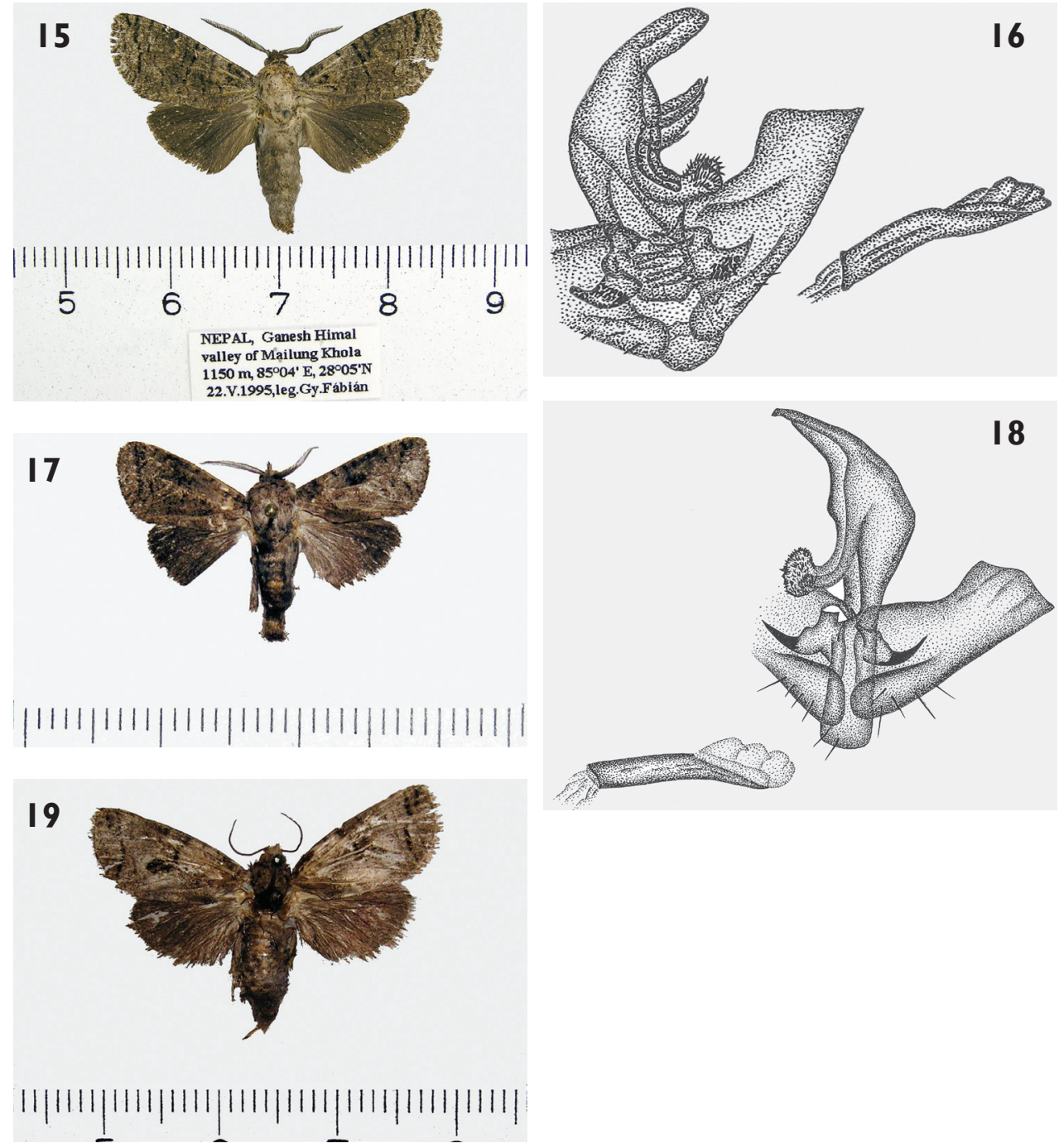

Figures 15-19. Patoptoformis spp. adults and genitalia. 15 P. ganesha (Yakovlev, 2004, holotypus 16 P. ganesha, holotypus male genitalia $\mathbf{I}$ P. hanuman Yakovlev, 2006 holotypus, male $\mathbf{I 8} P$. hanuman, holotypus, male genitalia $19 P$. hanuman, paratypus, female.

Female genitalia. Unknown.

Bionomics and distribution. Known only from the China's Sichuan province on the eastern edge of the Tibetan plateau. Patoptoformis rimsaitae is likely endemic to West Sichuan. A single male was attracted to light at an altitude of $3700 \mathrm{~m}$. The new species was collected in the shrubby transition between the mountain primary mixed forest and the alpine grassland zones (Fig. 14). Nothing is known about the early stages.

Etymology. The species is named in honor of Dr Jolanta Rimsaite, a prominent expert of general entomology. 
Key to species Patoptoformis based on external characters

$1 \quad$ Forewings dark brow with reticulated patterns formed by black lines..........2

- $\quad$ Forewings dark brown without reticulated patterns but with big black patch

2 Forewings grey black with yellow patch $P$. rimsaitae sp. n., China: Sichuan

- $\quad$ Forewings with row of narrow transversal bands in medial and submarginal zones

P. ganesha (Yakovlev), Nepal

Key to species Patoptoformis based on male genitalia

1 Arms of transtilla hook -like, thin

- $\quad$ Arms of transtilla hook -like, massive... P. hanuman Yakovlev, India: Assam

2 Tip of valva flat, edges rounded ........... P. rimsaitae sp. n., China: Sichuan

- $\quad$ Tip of valva with pointed edge........................P. ganesha (Yakovlev), Nepal

\section{Checklist of the genus Phragmataecia}

\section{Phragmataecia albida Erschoff, 1874}

= Pragmataecia erschoffi Reisser, 1962

Distribution. Iran, Turkmenistan, Uzbekistan, Kazakhstan, NW China (Kuldja), Afghanistan, SW Russia (S. Volga reg.) (Christoph 1884, Daniel 1963, 1965, Falkovitch 1986, Gross 1925, Uvarov 1910, Yakovlev 2005a, 2009).

Phragmataecia andarana Clench, 1959

Distribution: Namibia, South Africa (Vári et al. 2002).

Phragmataecia anikini Yakovlev, 2011

Distribution: SW Mongolia (Hovd aimak, Dzhungarian Gobi desert) (Yakovlev 2011).

Phragmataecia annapurna Yakovlev, 2009

Distribution: Nepal (Annapurna Himal) (Yakovlev 2009a).

Phragmataecia brunni Pagenstecher, 1892

Distribution: E. Africa (Tanzania) (Pagenstecher 1892).

Phragmataecia castaneae (Hübner, 1790)

= Phalena $($ Bombyx $)$ arundinis Hübner [1802-1808]

= Phalena castanea, Esper (1807) 
= Phragmatoecia castanea Teich, 1884

= Phragmataecia castanea sicca Dannehl, 1829

= Phragmataecia castaneae $f$. fusca Lempke, 1961

= Phragmataecia castaneae leonadae Gomez Bustillo, 1977

= Phragmataecia meloina Gomez Bustillo \& Fernandes-Rubio, 1976

= Phragmataecia sica Gomez bustillo \& Fernandes-Rubio, 1976

Distribution: Central and Southern Europe, S. England, M. East, Caucasus, Transcaucasia, Turkmenistan, Kazakhstan, NW Iran, Iraq, Syria, Lebanon, Turkey, W. China, SW Siberia, Egypt, Tunisia, Morocco (Yakovlev 2011).

\section{Phragmataecia cinnamomea Wileman, 1911}

= Xyleutes Hansi Strand, 1915.

Distribution: Taiwan, S. China (Jianxi-Fujian border) (Gaede 1933, Ueda in Heppner et Inoue 1992, Wang \& Lee 1998, Yakovlev 2009b).

Phragmataecia dushman Yakovlev, 2009

Distribution: Afghanistan (Yakovlev 2009a).

\section{Phragmataecia furia Grum-Grshimailo, 1890}

Distribution: Uzbekistan, Tadzhikistan ?, Afghanistan (Daniel 1964).

\section{Phragmataecia geisha Yakovlev, 2011}

Distribution: Japan (Yakovlev 2011).

\section{Phragmataecia gummata Swinhoe, 1892}

= Phragmatoecia (sic!) lata Snellen, 1895

= Phragmatoecia (sic!) sordida Snellen, 1901

Distribution: China (Fukien, Lingping), Vietnam, Thailand, Indonesia (Java, Sumatra) (Daniel 1940, Gaede 1933, 1949, Roepke 1957, Yakovlev 2009b, Yakovlev, Witt 2009).

\section{Phragmataecia gurkoi Yakovlev, 2007}

Distribution: NW Pakistan (Yakovlev 2007a).

\section{Phragmataecia fusca Wileman, 1911}

= Phragmataecia obscura Wileman, 1911

Distribution: Taiwan (Ueda 1992), Thailand, Hong Kong (Ades and Kendrick 2004).

\section{Phragmataecia fuscifusa Hampson, 1910}

Distribution: Sierra Leone, Nigeria (Yakovlev 2011). 
Phragmataecia hummeli Bryk, 1942

Distribution: China (NE Sichuan) (Yakovlev 2009b).

\section{Phragmataecia impura Hampson, 1891}

Distribution: India, Nepal, S. China (Hainan Isl., Zhejiang and Guangxi prov.), Vietnam, Laos, Thailand, Java (Snellen 1901, de Joannis 1929, Arora 1976, Yakovlev 2004, 2009b, Yakovlev \& Witt 2009).

Phragmataecia innominata Dalla Torre, 1923

=Phragmatoecia reticulata Hampson, 1910

Distribution: South Africa, Mozambique, Malawi (Schoorl 1990, Vári et al. 2002).

\section{Phragmataecia innotata (Walker, 1865)}

Distribution: China, Vietnam, Laos, Thailand (Yakovlev, Witt 2009, Yakovlev 2011).

Phragmataecia irrorata Hampson, 1910

Distribution: Zimbabwe, South Africa, Namibia, Bostwana, Mozambique, Zambia, Malawi (Pinhey 1979, Vári et al. 2002, Yakovlev 2011).

\section{Phragmataecia itremo Viette, 1974}

Distribution: Madagascar (Viette 1974).

Phragmataecia laszloi Yakovlev, 2009

Distribution: Nepal (Annapurna Himal) (Yakovlev 2009a).

Phragmataecia longivitta Ćandèze, 1926

Distribution: Laos (Ćandèze 1926).

\section{Phragmataecia minima Hampson, 1891}

Distribution: S. India (Hampson 1891).

Phragmataecia minor Moore, 1879

Distribution: Bangladesh, Myanmar ?, China (Lingping) (Cotes, Swinhoe 1887, Swinhoe 1890, Daniel 1949, Yakovlev 2011).

Phragmataecia monika Saldaitis \& Yakovlev, sp. n.

Distribution: China Zhejiang province.

Phragmataecia okovangae Clench, 1959

Distribution: Namibia, South Africa (Vári et al. 2002). 
Phragmataecia pacifica Yakovlev, 2007

Distribution: Russia, Caucasus, Daghestan (Yakovlev 2007b).

Phragmataecia parvipuncta (Hampson, 1892)

Distribution: India, Sri Lanka, Vietnam (Arora 1976, Gaede 1933, de Joannis 1929, Yakovlev and Witt 2009).

\section{Phragmataecia pelostema (Hering, 1923)}

Distribution: Togo, Cameroon, Nigeria (Yakovlev 2011).

Phragmataecia pectinicornis (Strand, 1914)

Distribution: Central Sudan (Strand 1914).

Phragmataecia psyche (Le Cerf, 1919)

Distribution: Benin? and different parts of Western Africa (Yakovlev 2011).

Phragmataecia purpureus Fletcher, 1927

Distribution: India (Bihar) (Arora 1976; Fletcher 1927).

\section{Phragmataecia pygmaea Graeser, 1888}

Distribution: SE Russia, Korea, NE China (Charbin) (Staudinger 1892, Staudinger \& Rebel 1901, Witt 1985, Yakovlev 2005b, 2009b).

Phragmataecia roborowskii Alpheraky, 1897

=Phragmataecia longialatus Hua, Chou, Fang \& Chen, 1990

Distribution: NW China, S. Mongolia (Yakovlev 2007c).

\section{Phragmataecia saccharum Moore, 1879 (Walker, 1865)}

Distribution: India (Cotes and Swinhoe 1887).

Phragmataecia sericeata Hampson, 1910

Distribution: Ghana, Nigeria (Yakovlev 2011).

Phragmataecia sumatrensis Snellen, 1892

Distribution: Indonesia (Sumatra) (Snellen 1892, Gaede 1933).

Phragmataecia terebrifer Fletcher, 1927

Distribution: India (Fletcher 1927).

Phragmataecia turkmenbashi Yakovlev, 2008

Distribution: Turkmenistan (Kopetdagh Mts., Valley of Ipay-Kala ) (Yakovlev 2008). 


\section{Checklist of the genus Patoptoformis}

Patoptoformis ganesha (Yakovlev, 2004)

Distribution: Nepal, Ganesh Himal.

\section{Patoptoformis hanuman Yakovlev, 2006}

Distribution: NE India, Assam.

\section{Patoptoformis rimsaitae Saldaitis \& Yakovlev, sp. n.}

Distribution: province China, Sichuan.

\section{Acknowledgements}

The authors are especially grateful to Mr Robert Borth (Milwaukee, United States) for English grammar suggestions, Ms Lina Jasiukonyte for ink drawings, Mr Janos Babics (Budapest, Hungary) for genitalia preparations, pictures and very useful suggestions on genitalia comparisons, Mr Alessandro Floriani (Milan, Italy) for providing habitat information and photos of Qin Liang Feng Shan mountains and to anonymous reviewers.

\section{References}

Ades GWJ, Kendrick RC (2004) Hong Kong Fauna: A checklist off selected taxa. Fauna Conservation Department, Kadoorie Farm an d Botanic Garden Corporation, 84 pp, http://www.kfbg.org/content/81/12/1/Checklist\%20of\%20Hong\%kong\%20Fauna\%20 $\% 282$ nd\%20edition\%29.pdf

Arora GS (1976) A taxonomic revision of the Indian species of the family Cossidae (Lepidoptera). Records of the Zoological Survey of India 69 (1-4): 1-160.

Ćandèze L (1926) Lépidoptères Hétérocères de l'Indochine Française. Encyclopédie Entomologique. Serie B. III (2) Lepidoptera. Recueil d'etudes biologiques et systematiques sur les Lépidoptères du Globe. Paris, P. Lechevalier, 122 pp.

Christoph H (1884) Lepidoptera aus dem Achal-Tekke-Gebiete. Mémoires sur les Lépidoptères rédigés par N.M. Romanoff 1: 93-138.

Chneour A (1955) Macrolépidoptères de Tunisie IV - Bombyces. Bulletin de la Société des Sciences Naturelles de Tunisie 8 (3-4): 287-289.

Cotes EC, Swinhoe C (1887) Cossidae. In: Cotes EC \& Swinhoe C A Catalogue of the Moths of India. II. Printed by order of the Trustees of the Indian Museum, Calcutta, 232-234.

Daniel F (1940) Die Cossidae und Hepialidae der Ausbeuten Höne (Lep. Het). Mitteilungen der Münchner Entomologischen Gesellschaft 30: 1004-1020.

Daniel F (1949) Die Cossidae und Hepialidae der Ausbeuten Höne (Lep. Het). Mitteilungen der Münchner Entomologischen Gesellschaft 35-39: 14-15. 
Daniel F (1963) Ein Beitrag zur Spinner- und Schwämer-fauna des Iran und Afganistans. Zeitschrift der Wiener Entomologischen Gesellschaft 48: 145-155.

Daniel F (1964) Cossidae aus Afganistan (Lep.). Opuscula Zoologica 77: 1-8.

Daniel F (1965) Österreichische Entomologische Iran-Afganistan-Expeditionen. Beiträge zur Lepidopterenfauna, Teil 4. Weitere Beiträge zur Bombyces et Sphinges Fauna. Zeitschrift der Wiener Entomologischen Gesellschaft 50: 121-145.

Falkovitch MI (1986) Lepidoptera from Kuldzhuktau Mountain and submountain plain, (southwest Kyzylkum). Fauna Cheshuekrylykh (Lepidoptera) SSSR [USSR]. Trudy Vsesoyuznogo Entomologicheskogo Obshchestva 67: 131-186. [In Russian]

Fletcher TB (1927) Report of the Imperial entomologist. Scientific Reports of the Agricultural Research Institute 1926-27: 56-67.

Gaede M (1933) Cossidae. In: Seitz A (Ed) Die Gross-Schmetterlinge der Erde. Die Spinner und Schwärmer des indo-australischen Gebiets 10. Alfred Kernen Verlag, Stuttgart, 809-823.

Gross C (1925) Beitrag zur Kenntnis der Lepidopteren-Fauna des mittleren rechtsseitingen Wolga-Gebietes. Verzeichnis der in der Umgebung von Chwalynsk a/Wolga, Gouvernement Saratow, gesammelten Macrolepidopteren. Internationaler Entomologischer Verein. Frankfurt am Main 1924/25, 53-95.

Hampson GF (1891) The Lepidoptera Heterocera of the Nilgiri district. London. Illustrations of typical specimens of Lepidoptera Heterocera in the collection of the British Museum 8. Printed by order of the Trustees, London 11, 66-67.

Heppner JB, Inoue H (1992) Lepidoptera of Taiwan. Vol. 2. Part 2: Checklist. Association of Tropical Lepidoptera \& Scientific Publishers, Gainesville, 27.

Joannis de J (1929) Lépidoptères Héterocères du Tonkin. Annales de la Societe Entomologique de France 98: 361-552, 559-560.

Newman E (1850) Economy of Zeuzera Arundinis. Zoologist 8: 2931.

Pagenstecher A (1892) Lepidoptera gesammelt in Ost-Afrika 1888/89 von Dr. Franz Stuhlmann. Jahrbuch Hamburgischen Wissenschaftlischen Anstalten 10: 245.

Pinhey ECG (1979) Moths of Southern Africa: Description and color illustration of 1183 species. A. A. Balkema, Rotterdam, 273 pp.

Roepke W (1957) The Cossids of the Malay Region (Lepidoptera: Heterocera). Verhandelingen der Koninklijke Nederlandse Akademie van Weterschappen. Afdeeling Natuurkunde (Tweede Reeks). Deel LII (1). Noord-Hollandsche Uitg. Mij, Amsterdam, 60 pp.

Schoorl JW (1990) A phylogenetic study on Cossidae (Lepidoptera: Ditrysia) based on external adult morphology. Zoologische Verhandelingen 263 (1): 1-295.

Snellen PCT (1901) Enumeration des Lepidopteres Heteroceres receuillis a Java par Mr. M. C. Piepers avec des notes par Mr. P. C. T. Snellen. Tijdschrift voor Entomologie 43: 37-45.

Strand E (1914) Lepidoptera aus Ober-Aegypten und dem Aegyptischen Sudan. Archiv für Naturgeschichte 9 (A): 95-103.

Swinhoe C (1890) The moths of Burma. Part I. Transaction of the Entomological Society of London 1890: 161-199.

Ueda K (1992) Cossidae. In: Heppner J.B., Inoue H. Lepidoptera of Taiwan. Vol. 1. Part 2: Checklist. Association of Tropical Lepidoptera \& Scientific Publishers, Gainesville, 27. 
Uvarov BP (1910) To the Fauna of Lepidoptera of Transural Kirgiz steppe. Russian Entomological Review 10 (3): 161-169.

Vári L, Kroon DM, Krüger M (2002) Classification and Checklist of the species of Lepidoptera recorded in Southern Africa. Simple Solutions Australia (Pty) Ltd. Chatswood, Australia, $385 \mathrm{pp}$.

Viette P (1974) Deux nouvelles espèces de Cossidae de Madagscar (Lepidoptera). Nouvelle Revue d'Entomologie 4 (3): 211-213.

Wang HY, Lee JY (1998) Lepidoptera of Guisandao Islet. The I-Lan County Museum of Natural History, Ilan City, 166 pp.

Wileman AE (1911) New Lepidoptera-Heterocera from Formosa. The Entomologist 44: 148-152.

Witt T (1985) Bombyces und Sphinges from Korea, III. (Lepidoptera: Notodontidae, Thyatiridae, Limacodidae, Sesiidae, Cossidae). Folia entomologica hungarica 44 (2): 195-210.

Yakovlev RV (2004) Cossidae of Thailand. Part I. Atalanta 35 (3/4): 335-352.

Yakovlev RV (2005) New records of distribution and systematic of Cossidae (Lepidoptera) of Europe and adjacent territories. Eversmannia 3/4: 18-27.

Yakovlev RV (2005b) Carpenter-moths (Lepidoptera, Cossidae) of Korean Peninsula. Euroasian Entomological Journal 4(4): 341-344.

Yakovlev RV (2006) New Cossidae (Lepidoptera) from Asia, Africa and Macronesia. Tinea 19 (3): $188-213$.

Yakovlev RV (2007a) New species of Palaearctic Cossidae (Lepidoptera). Eversmannia 10: 3-23.

Yakovlev RV (2007b) Carpenter-moths (Lepidoptera: Cossidae) of Russia. Eversmannia 9: 1133.

Yakovlev RV (2007c) New data about Cossidae (Lepidoptera) of Mongolia. Animal World of Fare East 6: 78-79.

Yakovlev RV (2008) New species of Palaearctic and Oriental Cossidae (Lepidoptera) II. New species of Phragmataecia Newman, 1850 from Turkmenistan. Eversmannia 15/16: 47-48.

Yakovlev RV (2009a) New taxa of African and Asian Cossidae (Lepidoptera). Euroasian Entomological Journal 8 (3): 353-361.

Yakovlev RV (2009b) New Cossidae for Chinese fauna (Lepidoptera). Eversmannia 17/18: 54-56.

Yakovlev RV, Witt T (2009c) The Carpenter Moths (Lepidoptera, Cossidae) of Vietnam. Entomofauna 16: 11-32.

Yakovlev RV (2011) Catalogue of the Family Cossidae of the Old World (Lepidoptera). Neue Entomologische Nachrichten 66: 1-130. 